\title{
DEFINING ACCOUNTABILITY IN A NETWORK SOCIETY
}

\author{
Mollie Painter-Morland
}

\begin{abstract}
This paper challenges some of the basic epistemological assumptions that underpin our current conceptions of accountability. Recent legislative developments like Sarbanes-Oxley attempt to enhance accountability in the business environment through the employment of checks and balances and the threat of individual liability. This kind of legalistic strategy still seems to assume the existence of an individual agent who employs moral principles to come to decisions in a deliberate, impartial manner. This paper will emphasize that moral decision-making often does not take place in this manner, but is rather a tacit process of sensing what the appropriate behavior would be. Accountability, both with respect to individuals and organizations, is less a matter of "accounting for" a set of concrete assets, than a question of being accountable to a set of internal and external stakeholders, or in terms of the tacit sense of moral propriety that develops among business associates and colleagues over time.
\end{abstract}

\section{Introduction}

W

hen things go wrong, society wants to hold someone, or something, accountable. It is as if we feel more secure when we can blame, shame and punish someone. Institutionalizing stricter rules that facilitate this punitive impulse seems to reassure us that we have done what we can to avoid recurrence of such problems. The aftermaths of ethical failures like Enron and WorldCom provide telling examples of this strategy. Corporate agents were held responsible and punished, and stricter penalties and tighter procedures were institutionalized through new legislation like Sarbanes-Oxley (SOX). Though such measures cannot rectify the harm done, or compensate the victims, they theoretically make executives and their subordinates more aware that they will be held accountable for the ways in which their day-today actions and decisions play out in the marketplace. At the very least, it is hoped that these strategies will instill some kind of fear of punishment that will serve to curtail unethical behavior. Part of the comfort that is to be had in finding someone or something to blame, is that it allows us to believe that the cause of the harm has been identified and that the root of the problem has therefore been addressed. In reality, however, such an approach may do little more than scratch the surface when it comes to addressing accountability failures in the contemporary business environment. 
This regulatory, preventive strategy is based on a number of questionable assumptions. In the first place, it assumes that there is a direct cause and effect relationship between the decisions of individuals and organizations and the negative consequences of those decisions. It also conceives of particular decisions and actions as the deliberate responses of rational individuals. In order to exercise the rational capacity that is ascribed to them, individuals have to possess a clear understanding of the principles or values that organize social life within a particular society, and the concrete behavioral parameters these values impose on daily life. The understanding of accountability that informs the impulse to legislate is based, in part, on the belief that decision-makers can develop a clear, objective conception of "right" and "wrong." It is also supported by a third assumption: that stricter rules can assist executives and organizations to exercise greater control over the actions and decisions of their employees and that fear of punishment would disincentivize misconduct.

In what follows, these implicit assumptions will be critically examined. I will argue that they are unable to offer a convincing account of the dynamics of contemporary business life as ordinary practitioners experience it from day to day. For one thing, business events are not always susceptible to the kind of simple cause-and-affect analysis that punitive regulatory prevention strategies require for their efficacy. Such events often emerge as anomalous side effects of the multidirectional interaction of a large number of diverse actors or institutions. In such business environments, it is the erratic dynamics of the system as a whole that determine the meaning and significance of particular actions and decisions, rather than individual decision-makers. Furthermore, I submit that the ideas and actions of decision-makers or moral agents are generated through the complex interactions of various conscious and subconscious, corporeal and mental, social and subjective perceptions. The assumption that the ideal moral decision-maker is an individual who is able to remain impartial by deliberately ignoring such perceptions, will therefore be subjected to critical scrutiny.

The assumption that rational individuals will agree on the universality of certain moral maxims, and that they will have the ability to consider in abstract terms the reasonable consequences of actions, has become the bedrock of many of our beliefs around accountability. I will argue that such assumptions are both practically and philosophically flawed. In practice, more and more corporate scandals seem to indicate that legal theory and compliance-driven ethics interventions fail to engender accountability on both individual and corporate levels. Philosophically, a lack of understanding about the nature of accountability under contemporary business conditions may be partly responsible. This state of affairs can be addressed only by looking very closely again at what exactly is assumed and presumed when we speak of accountability. Such a reconsideration of accountability is not aimed at the suspension of normative judgments. Instead it should be seen as part of an effort to find a more appropriate way to define normative boundaries and moral agency in contemporary business life. To this end, this paper will attempt to redefine accountability as a kind of contingent responsiveness to emergent stakeholder concerns and interests. 


\section{Accountability and the Dynamics of Contemporary Business Life}

In the opening statement of his book, The Moment of Complexity, Mark Taylor alerts us to the fact that we are living in "a moment of unprecedented complexity, when things are changing faster than our ability to comprehend them" (Taylor, 2001: 3 ). This statement not only reflects the precariousness of our existence within systems and structures, but also the vertigo that we experience when we lose our ability to understand its dynamics. In the information age we are continually bombarded with more information than we can coherently process. One of the consequences of our inability to adequately organize our experience is that worn-out paradigms, systems and structures, and the beliefs that support them, remain largely unchallenged in our thinking.

A central issue that may prolong some of the misconceptions around accountability is the way in which legalistic approaches to enhancing corporate ethics force us to regress to a mechanistic response to the problems that confront us. Taylor points out that this mechanistic understanding of how the world functions is based on Newtonian physics (Taylor, 2001: 24). Newton describes the physical universe, as well as society and culture, in terms of intrinsically stable and self-enclosed systems. Within such systems, universal laws ostensibly allow the objective observer to reliably describe and accurately predict strict cause and effect relationships between particular actions and events. From this mechanistic perspective, it would be possible, and indeed necessary, to distinguish between objective fact and biased opinion, between public commitments and private allegiances and between "right" and "wrong" when various possible courses of action are weighed against each other. Accountability from a mechanistic perspective allows us to rely on the ability of a business practitioner or executive team to consider in an unbiased fashion only the objective facts that pertain to a given situation, and to act strictly in accordance with the mandate afforded by professional or legal codes. This notion of accountability assumes direct cause and effect relationships, bases judgment on a factual analysis of right and wrong and encourages rule-driven behavior. It is these assumptions that underpin the confidence placed in legislation like SOX to prevent accountability failures. In the process, this legalistic strategy sustains a variety of misconceptions about how organizations and individuals within them actually function.

Understanding the world in Newtonian terms has direct implications for how legality and morality are interrelated. Within a closed system governed by a set of immutable rules, one can in fact argue that the right thing to do is to figure out the rules and follow them. However, Newton's worldview has long been replaced by a more organic way of understanding both natural and social systems. Hence, the way in which legality has become a synonym for morality must be reconsidered. Contrary to Newton's theories, natural and social scientists, as well as philosophers, came to the conclusion that neither natural nor social nor cultural systems were in fact closed. In the field of science, complexity theorists challenged the prevailing belief in a world composed of closed, deterministic structures and began to develop an alternative view. They proposed that natural forces and organisms, as well as 
individual and collective human life could be described more meaningfully in terms of the dynamics of so-called complex adaptive systems.

Complex adaptive systems are open, changing and continually responding to new developments. Though order still emerges from within them, they cannot be reduced to the sum of their components. Parts within the whole connect in multiple ways, with components interacting both serially and in parallel. These systems are non-linear and operate far from equilibrium (Cilliers, 1998). Importantly, they are not at all structured as orderly, rule-governed grids.

From the perspective of this more complex model then, the conventions and expectations that organize and guide business activity come into being and are developed as people interact with one another. Such order as exists within business life reflects, then, the "internal logic" of business as a system of functional relationships between various individuals and organizations. The advantage of this more organic understanding of business is that it looks for signs of functional organization within the dynamics of business activity itself, instead of trying to force it to conform to some preconceived operational model. As such, it has the potential to provide a far more relevant and appropriate understanding of the dynamics of business activity than mechanistic models. In "Complexity and the Role of Ethics in Health Care," Mills, Rorty, and Werhane analyze the actual and potential damaging effects of approaching adaptive systems mechanically (Mills, Rorty, \& Werhane, 2003: 7-8). Whereas mechanical systems assume that one can predict in great detail the interaction of each part given a particular stimulus, social systems such as healthcare organizations, are characterized by a number of complex functions, processes, and roles, where objectives are often divergent, and power is diffuse. As a result, the parts of the system respond to stimuli in unpredictable ways. It would be a mistake to view these unpredictable responses as errors, since it is often precisely through these responses that creative solutions to problems emerge.

Another objection to a mechanistic understanding of business is that it offers too simple and inflexible a way of establishing the value of certain dimensions of the organization. For instance, from the perspective of those who subscribe to a mechanistic view of business, the individual corporate executive or management team is supposed to be able to base his/her/its decisions on a full and objective understanding of only the hard "facts." A command of the facts is, however, often gained solely through a survey of the terse debit and credit entries that are encoded in the double entry accounting system. The problem with this approach is that the positive and negative values of particular behaviors and decisions cannot readily be assessed in terms of this limited paradigm. The double entry accounting system is unable to adequately account for so-called "intangibles." Markets today are driven as much by perception as by analysis, and the value of brand and reputation in such an environments is as important as it is non-quantifiable. The trust and respect that organizations or individuals come to command within the business environment are often simply the cumulative effect of countless acts of personal investment in the intangible quality of relationships. Since the effects of these actions are often 
not immediately apparent, it is difficult, if not impossible, to assess their value in simple concrete terms. To discount them though, would be to ignore one of the major factors that drives business activity today. The numbers may therefore fail to reflect the true state of a business organization's affairs or even create an entirely false impression of its health and prospects. It can be argued then that the distinction between objective facts and subjective opinion that is assumed to be so self-evident in the mechanistic view, has become blurred in contemporary business life.

Other macro-economic factors contribute to a business environment that function more like a complex adaptive system than like a mechanistic, rule-governed whole. Within the U.S., the overall trend has been toward radical deregulation. Since the Carter administration, the U.S. economic policy environment has been characterized by the easing of bureaucratic control and the decentralization of the economy, making it a more open and dynamic system (Taylor, 2004: 153-54). Organizations are given more freedom to explore new partnerships and associations and to take the initiative in gaining competitive advantages over their competitors. This often has the effect of stimulating innovation and creating complex and interdependent cooperation networks. As companies seek and terminate strategic partnerships and as they introduce new strategies and products, the economic landscape is constantly transformed, making business a far more volatile and uncertain affair.

In this dynamic network of reciprocal business relations, organizations and the market as a whole are open to manipulation by those who possess the necessary information and are able to play the confidence game well. Taylor cites Brian Cruver's book, The Anatomy of Greed: The Unshredded Truth from an ENRON Insider to draw attention to the risks involved in these new business dynamics (Taylor, 2004: 147). The book describes how Enron newcomers were inducted into the company by learning the first all-important principle: "At Enron perception is everything." Enron executives also boasted that with Republicans in the White House, deregulation was the law of the land. What this demonstrates is that a dematerialized and deregulated economy can create new forms of risk and different kinds of challenges. It is very difficult, if not impossible, to regulate perception through rule-driven interventions. In an environment where "perception is everything," business practitioners may have to find new ways of protecting themselves and their investors from those who would recklessly abuse their confidence.

The case of fifteen-year-old Jonathan Lebed, who succeeded in manipulating the market from his bedroom in Cedar Grove, New Jersey, serves to illustrate the inadequacy of our current legislative measures for insuring investors' interests. When confronted by the SEC, Jonathan argued that he wasn't doing anything that everyone else was not also doing or attempting to do. All stock investors, he insisted, try to influence the market's perception in their own favor. Why was he being punished for his success? And how, he asked, could the regulators at the SEC be so sure that his transactions alone were responsible for particular fluctuations in certain stock prices when there were so many factors and players involved in the market? Jonathan's case shows how difficult it is, under current conditions, to establish the 
kind of direct causal links between specific events and particular actions that are required to assign accountability.

The network society presents regulators with a conundrum. While privatization and deregulation fuel the economy and therefore need to be maintained, there is an increasing need for more control in order to prevent abuses. As a result, regulatory agencies are trying to curb the lack of accountability that has emerged by promulgating very stringent regulations in certain areas of business life. This knee-jerk reaction is a good example of the pendulum swinging too far in the opposite direction. Though understandable, it is a mistake to address the accountability crisis in a complex adaptive system by means of a rule-driven approach. The whole notion of accountability, as it is conventionally understood and applied in corporate legislation, must be revisited.

In order to understand the implications of the new business dynamics for the notion of accountability, it is necessary to consider their consequences for our understanding of moral agency. Who is the moral agent, the individual and corporate decision-maker to be held accountable? We must also reconsider what we mean when we say that an individual or business organization did the "right" thing. If the new dynamics of contemporary business activity challenge the way we think about individual accountability, they also compel us to reconsider the normative framework for holding people accountable.

\section{Challenges to Moral Agency and Moral Epistemology}

Our ability to hold individuals and organizations ${ }^{1}$ accountable for their decisions and actions depends on our understanding of why agents made certain decisions, as well as our judgment as to whether or not they gave proper consideration to the normative implications of their decisions and actions. Jones, Parker, and Ten Bos, in their publication For Business Ethics, argue that business ethics have "foreclosed" philosophy by restricting analysis to a very limited number of philosophers and almost completely excluding twentieth-century thought (Jones, Parker, \& Ten Bos, 2005: 3). As a result, business ethics as a discipline seems to have bought into a very specific notion of moral agency, namely that of the rational decision-making subject. This view of agency is essentially a product of the Kantian deontological approach, Bentham and Mill's utilitarian thinking, and Rawlsian "justice as fairness" principles. ${ }^{2}$ Two of the most prominent views of agency that result from a focus on these schools of thought are "rational choice theory" and "integrated social contracts theory" (Freeman \& Werhane, 1999). Both of these theories rely on the assumption that individuals can come to some conclusions on what constitutes moral behavior through deliberate rational analysis. The way in which prominent business ethicists discuss moral decision-making clearly displays this emphasis. Bowie describes being rational as essential to moral agency (Bowie, 1999: 45). He explains that rationality entails the utilization of the Kantian test of universality, i.e., that valid moral maxims will be accepted unanimously in an ideal kingdom of ends. 
He also views the ability to "see future consequences" and to "reason abstractly" as qualifying characteristics of humanity (1999: 62). Dreilinger and Rice put forward a systematic problem-solving model that starts with identifying the desired outcomes and carefully avoids subjectivity and personal perceptions that can create barriers to objectivity (Dreilinger \& Rice, 2001: 95-96). They stress that emotions get in the way of logic and suggests that one should avoid words like "fairness" or "doing right" since they carry an emotional content that might introduce bias.

These approaches to decision-making stress the importance of autonomy and impartiality. It may be helpful to understand the origin of these elements that are so central to the understanding of moral agency in business ethics. Their roots may be found in the deontological thinking that Kant introduced in his Groundworkfor the Metaphysics of Morals. Kant's ideal moral agent is the impartial, rational decisionmaker who depends on a priori reasoning processes to formulate universally true moral statements. The Kantian notion of the rational subject appeared to provide a solid basis for holding individuals accountable for their actions. It assumed that the decision-maker could function as an impartial individual, who would reach universal moral truths through the use of reason and therefore gain reliable knowledge of right and wrong, without the consideration of consequences.

Evaluating the moral appropriateness of a particular form of business behavior on the basis of the specific form and nature of the relationships that exist between particular individuals or within specific contexts would be permissible only for the formulation of hypothetical imperatives, but hypothetical imperatives are always trumped by categorical imperatives (Bowie, 1999: 64). Kantian theory therefore assumes that the mature moral agent should have the ability to step back from his/her immersion in role-responsibilities and employ the universalization test to judge the categorical validity of his/her decision. Even scholars who embrace the notion of moral imagination, like Werhane, argue that because organizational expectations may demand immoral acts from those fulfilling roles within the system, moral agents must be able to evaluate their role responsibilities from a more "common sense morality" (Werhane 1999). It is this assumption of the availability of "a common sense morality" that needs to be interrogated further.

Within organizations that function as complex adaptive systems, this view of moral agency and epistemology has become both practically and philosophically problematic. Developments in twentieth-century philosophy contested the ideas central to moral agency as described above, namely the importance of rational impartiality, as well as that of deliberate individual decision-making based on reason. Prominent critiques of Enlightenment subjectivity can for instance be found in communitarianism, poststructuralism and pragmatism. Due to the limited space available for such discussion within the confines of a journal paper, these approaches cannot be discussed in depth. What follows is an attempt to highlight the main implications of these critiques by summarizing the implications that the work of a few authors has for moral agency and epistemology. I will specifically refer to the Enlightenment critique of Alasdair MacIntyre, the pragmatist thought of Richard 
Rorty, the moral language theories of Mark Johnson and Verner Petersen and the genealogical thought of Michel Foucault.

MacIntyre puts forward his basic objections to Enlightenment's approach to justifying morality in his seminal texts After Virtue and Whose Justice, Which Rationality? In After Virtue he argues that Enlightenment approaches to morality, like that of utilitarianism and deontology, suffer from a deficient perspective on human nature, as well as a flawed epistemology. The main problem, according to MacIntyre lies in the fragmented conceptual scheme that Enlightenment thought employs (MacIntyre, 1981: 54). He argues that Enlightenment thought's rejection of a teleological view of human nature robbed it of the one element that moral statements require to make any sense, namely, a teleological context. If one has no notion of one's purpose and role within a specific context, judgment about the morally "correct" behavior becomes nonsensical. MacIntyre is not blind to the fact that defining morality only in terms of one's specific role harbors certain dangers. In his later work, MacIntyre makes us aware of the fact that many individuals today participate in a number of different "practices," which compel them to selectively exercise their moral agency in accordance with different kinds of role-responsibilities and obligations (MacIntyre, 1999: 321). He calls this phenomenon "compartmentalization," and is alarmed by the fact that individuals no longer seem capable or willing reevaluate their assigned role morality from the perspective of what it means to be human (1999: 317). But even in this appeal to always seek another, broader perspective, MacIntyre has a teleological scheme in mind. He emphasizes the importance of certain social structures in supporting moral agency. He believes that everyday milieus like the home are the kinds of contexts where agents engage in extended critical reflection with others about conflicts in virtues, or about issues like the meaning of life and death (1999: 324). This kind of social setting is crucial in creating the kind of agency that is capable of moral reflection. The "reframing" that takes place in and through one's multiple relationships with others is key in fostering moral responsiveness.

It is in this respect that pragmatism's insights into how moral progress takes place become invaluable. Rorty describes morality from a pragmatist perspective as follows: "Moral development in the individual, and moral progress in the human species as a whole, is a matter of re-making human selves to enlarge the variety of relationships which constitute those selves." (Rorty, 1999: 79). Moral development, as Rorty describes it, is a matter of increasing sensitivity and responsiveness to the needs of an ever-larger variety of people. Pragmatists reject the distinction that philosophers like Kant make between morality and prudence, and between reason and sentiment. Instead of constructing a foundation for moral truth on the basis of some arbitrary set of metaphysical first principles, pragmatists direct their efforts at the extension of existing networks of relationships. For Rorty the pragmatist emphasis in considering moral issues is on breadth, rather than depth (1999: 87). He compares this accommodating process of critical inclusion to the sewing together of a very large, elaborate, polychrome quilt. 
Insight into the functioning of moral decision-making lends further support to rejecting the notion of "pure" moral reasoning. Lakoff and Johnson (1999) and Verner Petersen (1999a, 1999b) have convincingly argued that our moral decisionmaking is in fact a far cry from an exercise in deliberate principled reasoning. They have done much to draw attention to the way in which historical contexts, social practices, metaphoric language, and our embodiment, shape the moral agent's judgments. According to Petersen, the moral fabric that facilitates social life within different contexts weaves itself, without a rational conductor (Petersen, 2002). Our moral judgments reflect tacit knowledge and social grammars of which we are seldom conscious. As such, they are often neither purposeful, nor willful. Moral knowledge is not gained through a decontextualized rationality, nor is it to be found in an analysis of the presumed structure that underlies all of reality. In fact, we seem to develop our moral sensibilities through an ongoing process of trial and error. Transmission and inculcation of moral values are not directional processes, but take place spontaneously. In Petersen's view children develop their personal sense of moral agency through a process that involves negotiating relationships with others and the world (2002). When one considers these observations, it becomes clear why leadership example is so crucial to the success of ethics interventions. Senior members of business organizations often provide moral guidance unconsciously, through their responses to the behavior of new colleagues and subordinates. Petersen draws attention to the crucial role that observing, imitating and participating play in the process of moral inculcation. As moral agents, we don't learn through explicit instruction, we rather experience patterns of co-variation for ourselves. The norms and values that are established in the process often resist articulation and formalization in a readily transmittable form, somewhat like giving someone a dictionary to learn a language. Such a person may end up knowing the vocabulary, but is unlikely to be able to use it in a meaningful way. The knowledge, awareness, and sensitivity to context of conversation can ultimately be gained only through the experience of interaction with others who speak the same language.

Foucault reiterates the important interplay between the subject, his or her context, and the power relationships in which he or she is embedded. He draws attention to the fact that certain institutional practices create discursive limits that determine what can be discussed within certain contexts (Foucault, 1972: 44). Our conceptual frameworks and categories are the result of specific power interests, but these are effectively concealed by the creation of "objective" categories and structures that "normalize" our institutional life. For Foucault, historical influences, power interests, conceptual frameworks, and institutional practices always inform individual moral judgments. Moral decisions are influenced by where decision-makers find themselves in terms of the corporate hierarchy, the discursive limits that come with a particular position, and the extent to which power relationships both restrict and enable the options available.

The question then remains: what are the guidelines that inform the moral agent's decisions? Instead of referring to some universal principles to define normative 
guidelines, complex adaptive systems display an inner purpose that has normative qualities. Intricate interrelationships hold the system together, and hence constitute the tacit moral fabric and values that inform the behavior of agents who are part of the system.

Frederick has defined values as "enduring beliefs about preferable states of existence" (Frederick, 1995). They express and articulate, "those things we care about and that we think create a better world." As expressions of the relationships that exist within the network, these values are relational through and through. However, the development of moral values within a business organization is not simply a dressed up form of relativistic emotivism. Nor is it a soft-focus kind of determinism that forces the individual agent, or the organization as agent, into a monodiscursive straitjacket. Individuals actively contribute to the organizational culture and the interactions between moral agents continually contribute to the moral fabric of the broader network. providing critical perspectives on each other. This multiple interaction of agents within and without the system contributes to the creation of a moral fabric that allows for self-referentiality, order and stability.

By participating in the creation of a business organization's moral fabric individual employees are, in a very real sense, writing their own history, creating their professional world, and continuing to fashion the future of the institution. As Collins and Porras argue in Built to Last, a successful company succeeds in fostering a "reason for existence" amongst its members (Collins \& Porras, 2002). It builds on certain core values, or enduring beliefs, but is also committed to a particular purpose, i.e., a desire to add something exceptional to human existence. Collins and Porras seem to see the creation of purpose as a leadership function, the effects of which can influence organizational dynamics. Without discounting the importance of leadership example, the emergence of normative orientations within organizations may be a more complex affair. I propose that the sense of shared purpose that exists within a business organization is born at the intersection of its collective memory, its leaders' initiative and example, the various contextual variables that inform and limit its endeavors, and the relationships that it builds and maintains with its host community and other stakeholders. It entails a responsiveness that allows the corporation to establish its sense of morality, and its decisions about appropriate actions. The question that must be posed is, "Who are we now, and how do we respond to the 'others' that confront us?"

Johnson \& Johnson is a corporation that has been praised for the way it remains "true" to its organizational identity and its credo. Business ethicists often assume that this is a result of the deliberate application of J\&J's principles to various cases. However, an analysis of the corporation's behavior may actually show that it defines its responsibilities relationally. It may be quite significant that J\&J's values statement is called a credo, and not a "code." It starts with their responsibility towards those who use their products. But instead of referring to these users through the generic term "customers," they are listed in terms of their various role-responsibilities, i.e., doctors, nurses, mother and fathers. Their credo ends with a statement that reflects 
the spirit of experimental pragmatism: "Our final responsibility is to our stockholders. Business must make a sound profit. We must experiment with new ideas." Johnson and Johnson also stress the importance of diversity in their organization, and their definition of diversity reflects an insight into the fact that people do not fall into neat categories like "us" and "them." They define diversity as "a variety of similar and different characteristics among people." In response to moral dilemmas like the Tylenol case, the corporation seems to identify the appropriate response by evaluating whether it allows them to sustain important relationships. The case of Johnson and Johnson shows that this relational responsiveness has to be sustained over time in order for a strong sense of normativity to emerge. On their website, various iterations of their credo as it was adapted over time appear. Hence the normative identity of the corporation is constantly at stake. The daily decisions of a complex network of stakeholders will determine whether what arises and passes away is "good" or "bad."

One significant objection to defining a values system as an emergent property of a complex adaptive system is the risk that the system itself is prone to a kind of solipsism, which would make criticism of its ethos impossible. What safeguards the organizational system against the potentially harmful effects of such insularity is the fact that complex adaptive systems are organized as open networks of relations. As such they cannot function in isolation. They are therefore unlikely to devolve into deterministic environments that undermine the possibility of dissent and criticism. Participation in complex adaptive systems also exposes the moral agent to a plurality of perspectives that result from the network of relations within which the individual is embedded. The various systems that agents inevitably participate in may actually subject them to a number of competing and contradicting demands. Foucault would argue that it is never really possible to develop an independent vantage point from which one can objectively assess the moral implications of one's fulfillment of contradictory role expectations (Foucault, 1994). Foucault would not, however, have perceived this as impairment to personal morality. He argued that our embeddedness and participation in institutions and practices actually constitute the conditions of freedom which make ethical responses possible. The fact that we participate in different systems of social relations makes us more aware of their respective limiting conditions. Olivier points out, in this regard, that the multiple discourses in and through which our subjectivities are constructed are bound to generate, at some point, the ability to exercise "free will" though certain "volitional discursive spaces," which provide a foothold from which dominant discourses may potentially be criticized (Olivier, 2003: 335). For Olivier, "the existence of intersecting alternative or counter-discourses allows one to escape the straitjacket of monodiscursive determinism." The fragmentation of experience that an open network of complex adaptive systems exposes the individual to thus facilitates the kind of critical autonomy that is a prerequisite for a relational understanding of accountability. 
What is crucial in moral decision-making today is not so much the availability of an immutable source of moral orientation or our ability to access it through the application of appropriate logical protocols, but rather our skill in managing and negotiating the various relationships within which we are enmeshed. Moral judgments need not depend on our ability to find an independent "vantage point" from which to establish the "right" course of action. "Accountable" agents are those decision-makers who take account of a specific situation in collaboration with other stakeholders and who are able to determine, in the course of this process, the specific nature of their accountability.

\section{Reconsidering Accountability within an Open Network of Business Relations}

The contribution that this paper hopes to make lies in its insistence that these philosophical perspectives, combined with the dynamics of the current business environment, precipitate an urgent reconsideration of how we talk and write about, as well as act on, notions of accountability. A new understanding of accountability requires an awareness of the relational context within which responsibilities and duties develop. It demands an acknowledgement of the dynamic network of interactive relationships within which individuals and organizations are embedded in the business environment, as well as a willingness to seriously consider the very consequential role and effect of expectations and perceptions within such a context. What is required is a broadening of our understanding of accountability. We usually think of moral agents as being accountable for something. However, considering the interactive way in which moral knowledge comes about and moral decisions are made, we may need to re-envisage a moral agent as being accountable to others or in terms of some shared sense of normative propriety. The notion of being accountable "for" something is usually associated in the business environment with responsibility for a set of defined, concrete assets. There is, naturally, merit in this, but it is hardly sufficient within the context of an open network of interactive relationships where perceptions and other intangible dynamics play such a crucial role.

Individual business practitioners and organizations also need to consider whom they are accountable to in the determination of their moral duties. To do so is to acknowledge that much of the value of an organization is generated in and through cooperative business relationships and that the quality of these relationships may represent an organization's most valuable assets. The emphasis in such an approach is in the way in which a business organization and its employees engage with and respond to its partners and competitors within an extended network of reciprocal business relationships.

In addition, the nature and limits of an individual or organization's moral responsibility to those with whom they interact could be clarified if it were understood in terms of a particular relational form of moral orientation. This is an approach that remains cognizant of the fact that an individual's professional inclinations and an 
organization's moral priorities develop relationally in the course of the interpersonal interactions among agents within a system of relations as well as under the influence of contact with alternative perspectives that may enter the system from without. The tacit sense of reciprocal responsibility, loyalty and common cause that develops among colleagues and collaborators in this way may resist formal articulation in the form of rules and procedures, but it nevertheless forms the normative backdrop against which the actions and decisions of individuals and organizations become intelligible. As such, it is also an understanding of the nature of accountability that acknowledges the need for discretion and discernment. The actions and responses of individuals and organizations cannot adequately be appreciated or evaluated without considering the specific business episode and context within which it is situated and of which it is a part.

Redefining accountability has definite implications for the way in which one perceives business practice and it may therefore be helpful to consider what implementing these proposals may entail. A recent interview with author Alice Petersen, ${ }^{3}$ founder of a unique whistle-blowing service called "Listen-up," brought up an intriguing example of what it might mean, in concrete terms, for an organization to fulfill its moral responsibilities to those with whom it interacts in an open network of reciprocal business relations. According to Petersen, her company's research suggests that whistle-blowers tend to respond very negatively to the scripted responses that are usually employed by those whom companies contract to man whistle-blowing lines. These consultants are usually located in call-centers that serve a wide variety of clients with divergent needs. It is for this reason that pre-prepared scripts are employed. They are designed to ensure responses that are considered consistent and appropriate to the issues that need to be addressed in the course of the consultation. The agents who answer calls are rarely instructed or trained to be responsive in a spontaneous way or to establish a relationship of trust with callers who have sensitive information. Instead scripted responses are used to identify, as quickly as possible, the issue at stake and to offer a standard solution or response. Whistle-blowers tend to take this as evidence that the organization does not take his/her/their unique situation seriously, or that it simply seeks as expedient a solution as possible to the problems raised. Standardized procedures of this nature therefore tend to send the message that the organization does not consider itself accountable to either the caller or the various stakeholders involved, but rather seeks to limit its liability for anything that might have gone wrong. Instead of adopting a relational perspective and recognizing that whistle-blowing is an act of loyalty, the organization places the whistle-blower in opposition to itself.

Petersen's firm developed an alternative service that allows for more responsive interactions with whistle-blowers. It recognizes the problem and acknowledges the fact that it arises in and from a unique set of circumstances and relationships. The agent who answers such a call would have to demonstrate that he/she cares about the whistle-blower's concerns and about the possible implications that it may have for all concerned. In addition, it is essential that such calls be treated with the utmost 
confidentiality and that the problems raised by them receive immediate attention. In this way the trust and confidence necessary for the system to function effectively develop over time. Such an approach takes the organization's responsibility to its employees and stakeholders seriously.

A more relational understanding of accountability also requires that the responsibilities and duties of the individual or organization be interpreted in terms of the tacit and flexible logic that continually informs their interaction with others in a system of reciprocal relationships. As such, it demands a new way of distinguishing morally appropriate and inappropriate behavior within the organizational context. The values that become manifest in the behavior of individuals within a particular organization represent an "emergent order" within a system of functional relationships. This "order" is unique in that it is not formulated in reference to some abstract and supposedly independent point of moral orientation, nor does any one agent or body within or outside of the organizational system unilaterally impose it. Instead it spontaneously emerges over time in and through the interaction of individuals who participate in the system. A more relational understanding of the responsibilities of the organization therefore requires that those who contribute to it, and participate in it, continually consider what they collectively care about, and make these priorities an integral part of the organization's operational goals. In other words, the organization needs to align its strategic goals and organizational values. In addition, care needs to be taken to ensure that some form of congruence exists between the moral priorities of the organization as a whole and the values of its individual employees.

In order that it should be a truly participative environment in which everyone assumes co-responsibility for the actions of everyone else as well as for the organization as a whole, it is crucial that all voices be heard. In the absence of a set of a-contextual, a-historical moral imperatives, it is important that communities of discernment come into being within the organization to assist individuals in their daily decisions. One could think of such communities as "clusters of responsibility," within which individuals accept co-responsibility for the creation of an organizational culture. According to Collier and Esteban the recognition of, and respect for "otherness" form the ethical glue which allows integration and participation in these communities of discernment and co-responsibility (Collier \& Esteban, 1999: 184). There is some support for Collier and Esteban's ideas in the work of Foucault. In his analysis of what he calls the "critical ontology of the self" Foucault claims that the development of the self is "kick started" by deliberate participation in "limit experiences." This involves exposing one's beliefs and values to risk by placing it on the table of dissent. Only in this way, argues Foucault, are we likely to become aware of how our potential has been limited by the internalization of particular discursive practices (Brewis, 1998: 65). Exposure to the critical light of dissent initiates a process of moral self-formation that does not have to rely on impersonal abstraction. Self-policing and self-motivation thus become possible. 
For Foucault this amounts to a form of "lived morality." The dynamics that Foucault describes here in connection with the moral development of the individual are of course equally valid with respect to the organization as a whole, which benefits in a similar way from exposure to dissent and difference. The multiple actions and interactions of its various agents combine to produce a tacit sense of moral selfhood, which makes it possible for colleagues to motivate and police one another through their mutual participation in the internal life of the organization. This kind of organization exercises its freedom and creativity in reference to a communication framework that connects organizational "purposing" and individual responsiveness. The ethical dimension of that communication framework resides in the fact that each individual is required to exercise moral judgment in decision-making.

Instead of trying to inculcate employees with some set of foundational principles, ethics training should be devoted to an open discussion about what is important to the organization and its various individual employees. Case studies that reflect everyday occurrences could be employed to facilitate such a discussion. It should challenge employees to define how they see themselves individually and collectively in particular situations, and ask them to consider what is important to assert and protect under such conditions. Debates on macro-ethical issues are not particularly useful within the context of this form of practical engagement. Situations that occurred in the organization's past and the personal experiences and recollections of participants are far more meaningful points of reference in developing an appropriate moral orientation within the organization. The kind of approach that this paper proposes allows no "passing of the buck." In a very real sense, the "buck" stops not only at the desk of every single employee, but also at the address of the organization as a whole. Corporations that encourage this kind of self-reflectivity therefore not only create internal environments that are conducive to responsible behavior, but also increase the likelihood that it will enjoy positive relationships with its external stakeholders and partners. By constantly working to improve the moral quality of its internal life, the organization creates agents that are capable of building relationships of trust with agents and institutions in a broader business network. It is these relationships that ultimately add value to the organization.

As a complex adaptive system, the organization's responsibilities to other participants in an open network of interactive relationships extend beyond the names on its payroll. An organization's external stakeholders are affected as much by its actions, perceptions and agendas as theirs affect the organization. It therefore has a duty to build and nurture relationships of trust and cooperation with these agents and institutions. As such it is accountable not only "to" its own employees, but also "to" its various external stakeholders. It is duty-bound to consider the effect of its decisions and actions on its relationships with a wider network of agents and institutions. Its aim should be to maintain relationships of trust and confidence with as broad a network of stakeholders as possible. To do so successfully, the organization would be compelled to take into serious consideration the impression that its actions and decisions are likely to make on its partners and constituencies. The task of the 
organization then is to try to determine what it has to do to gain and retain the trust and confidence of those with whom it interacts. A sustainable relationship is based on shared priorities and expectations, and it is therefore up to both the organization and its stakeholders to negotiate acceptable terms for their sustained association. The organization's duty to its external stakeholders therefore requires it to actively engage with them in order to continually develop appropriate protocols for their continued interaction and cooperation. These protocols then become the basis upon which the appropriateness of its various actions and decisions is assessed.

It is interesting to note how MacIntyre and the pragmatists' advocacy of the imperative to widen the circle of consideration in moral deliberation beyond the organization's internal system of relations corresponds with Ed Freeman's stakeholder model. Freeman makes a distinction between so-called "wide" and "narrow" conceptions of the stakeholders involved in corporate activity. The wide definition includes any group or individual who might be affected by the organization, whereas the narrow definition includes only those groups who are vital to the success of the organization (Freeman, 2001:163). Pragmatism's view of relational morality clearly favors the wide definition, i.e., an acknowledgement that the business organization is part of a wider network of relationships. To expect business organizations to take responsibility for the quality of their relationships with such a wide range of stakeholders has definite implications for the governance of corporations. If companies are to succeed in fulfilling their social responsibilities, boards will have to acquire the habit of asking, "What are the questions that we are not asking? What are we not being told?" The "facts" as they are presented may be misleading and boards therefore have to ask themselves, "What do we remain unaware of in and through what we are being told?" To recognize that the presentation of "facts" can be misleading means that boards can no longer simply rely on the opinion of "experts" to decide important issues pertaining to the operations of the organizations that they govern.

Phillips distinguishes between stakeholders to whom the organization has a moral obligation, i.e., normative stakeholders, and derivative stakeholders, whose actions and claims must be considered by managers because of their potential effects upon the organization and its normative stakeholders (Phillips, 2003: 30). The benefit of this insight is that it acknowledges the shifting boundaries of stakeholder relations that may result from power dynamics and complex interactions between the organization and various stakeholder groups. The "balancing" of these interests does not take place according to the principles of strict equality, ${ }^{4}$ but rather depends on the specific purpose of the stakeholder interactions. Obligation exists between discrete entities, rather than as a diffuse, all-encompassing concept (Phillips, Freeman, \& Wicks, 2003: 493). These insights reflect the realization that the notion of "stakes" and "relationships" can make sense only if there is an ongoing sensitivity to what moral responsiveness may require in each situation. There are no hard and fast rules within this new understanding of accountability. 
In visual representations of this network of stakeholder relationships, the organization typically is pictured in the center of the network of relationships, and this assumption often determines a corporation's perceptions of the importance of its own interest within moral deliberation. Understanding accountability as an ongoing responsiveness towards a broader group of stakeholders may entail drawing a more decentralized stakeholder map. The organization sometimes needs to assume a less central position, and to perceive itself as simply one partner in an interactive network of relations wherein everyone influences and is influenced by the dynamics of the system as a whole. From this perspective a more relational understanding of the organization's accountability towards its various stakeholders can develop. This perspective is echoed in the work of Phillips, Freeman, and Wicks, who describe stakeholder relationships as organic in nature, best served by the spirit of pragmatic experimentalism (Phillips et al., 2003: 496). Thinking about accountability requires openness towards unpredictable influences from stakeholders that may previously not even have been on the map. It wants the organization and the individual to respond intuitively to moral responsibilities as they are encountered. As dynamic, complex adaptive systems, contemporary business organizations' relationships with one another and with their other stakeholders are flexible and subject to continuous adaptation and renegotiation. It is for this reason that organizations are compelled to continue to engage their external stakeholders in a sustained process of participative cooperation. The duty of contemporary business organizations to sustain relationships of trust and confidence with their external stakeholders compels organizations to act in good faith in the course of these exchanges. One of the concrete implications of this duty relates to the sharing of information that could potentially affect the relationships among different agents and institutions. Information about an organization's decisions, actions, priorities and liabilities should be readily available to its external stakeholders so that they are able to adjust their expectations of the relationship in an appropriate way. The notion of "triple bottom-line reporting" represents a promising proposal in this regard. This model offers an exemplary vehicle for sharing information and inviting feedback about the organization's activities and priorities. As such, it deserves serious consideration.

As we become more aware of the way in which the internal dynamics of organizations like Enron contribute to moral failure, we begin to appreciate how an organizational culture can create dominant discourses which preclude the discussion of certain issues and systematically screen out the consideration of particular sets of stakeholders. Sherron Watkins, one of the whistle blowers in the Enron debacle, described the organization's culture as "intimidating" and "aggressive." It is easy to see how it would be difficult to develop and sustain a truly self-reflexive, open system within such an atmosphere. The Federal Sentencing Guidelines compel organizations to create an organizational culture that encourages ethical behavior. They make business organizations aware that they are accountable, not only for the actions of individual employees, but also for the internal culture that shapes and informs employees' moral sensibilities. If business organizations are to fulfill their 
responsibilities in this regard, they are well advised to direct their efforts toward creating an environment conducive to open interaction and development of a sense of shared responsibility.

\section{Conclusion}

Employing a rule-oriented approach through the promulgation of legislation like SOX is much like using a square peg to fill a round hole. Rules are unlikely to provide a meaningful source of moral orientation or a feasible basis for holding business practitioners and organizations accountable for their actions and decisions under current conditions. The complex dynamics of an open network of interactive business relationships are simply too demanding for such an inflexible form of moral orientation. It is no longer appropriate to think of the moral agent as an autonomous, impartial individual whose moral judgments are the deliberate rational operationalization of universal maxims. Under current conditions, it is more realistic to think of the moral agent as an individual whose understanding of the world and moral compass responds to the many different practices and relationships in which he/she is embedded. Today's business practitioner finds his/her moral orientation in the tacit sense of mutual responsibility and common cause that emerges in the daily interactions among colleagues and other stakeholders. Because of this a more flexible, relational understanding of accountability is required. From a relational perspective, the duty of the individual and organization is not only to take responsibility for a set of concrete assets, but also to be responsible to those stakeholders with whom they share a business relationship and in terms of the tacit sense of moral propriety that develops over time among colleagues and associates. These duties compel individuals and corporations to do everything they can to establish and sustain relationships of trust and cooperation with as many internal and external stakeholders as possible. In the process individuals and corporations will have to contend with dissent, contestation and uncertainty. Such however, are the demands of accountability in a complex business environment where an organization's prosperity and an individual's prospects may turn entirely on the on the quality of the relationships that they are able to build.

\section{Notes}

I would like to thank Pat Werhane, as well as the editors of this special section, Shawn Berman and Rob Phillips, and Associate Editor Norm Bowie, for their invaluable input in improving this manuscript.

1. The assumption upon which this argument relies is that the corporation can be viewed as a moral agent in much the same way that an individual can. It draws, in this regard, on the work being done in agency theory by authors such as Peter French. The article by Goodpaster and Matthews "Can Corporations Have a Conscience?" provides a rationale for extending moral agency to corporations (1983[2001]). 
2. Jones, Parker and Ten Bos, in their publication For Business Ethics, argue that business ethics has "foreclosed" philosophy through its focus on virtue-ethics, deontology and utilitarianism (2005:3).

3. Interview with Alice Petersen at the Listen-up head offices, Chicago, January 2005.

4. In this respect, what is being proposed here differs from what Bowie proposed in his analysis of "the firm as a moral community" (1999: 89). He argues that in a business firm organized as a moral community, the interests of every member are equal to the interests of every other member. This paper accepts that because of the shifting power relationships within a network, relationships are never equal. Inequality does however not undermine moral responsiveness. This paper also disputes the viability of Bowie's insistence on consensus among all members about categorical imperatives.

\section{References}

Bowie, N. E.1999. Business ethics: A Kantian perspective. Malden, MA: Blackwell Publishers.

Brewis, J. 1998. Who do you think you are? Feminism, work, ethics and Foucault. In Parker, M. (Ed.) Ethics and Organizations: 53-75. London: SAGE Publications.

Cilliers, P. 1998. Complexity and postmodernism. London: Routledge.

Collier, J., \& Esteban, R. 1999. Governance in the participative organisation: Freedom, creativity and ethics. Journal of Business Ethics, 21: 173-88.

Collins, T., \& Porras, J. I. 2002. Built to last: Successful habits of visionary companies. New York: Harper Business.

Dreilinger, C., \& Rice, D. 2001. Ethical decision-making in business. In Hoffman, W. M, Frederick, R. E., \& Schwartz, M. S. Business ethics: Readings and cases in corporate morality: 95-99. Boston: McGraw-Hill.

Foucault, M. 1972. The archeology of knowledge. New York: Pantheon Books.

Foucault, M. 1994. Foucault: Ethics, the essential works, vol. 1. London: The Penguin Press.

Frederick, W. C. 1995. Values, nature, and culture in the American corporation. Oxford: Oxford University Press.

Freeman, R. E. 2001. Stakeholder theory of the modern corporation. In Hoffman, W. M, Frederick, R. E., \& Schwartz, M. S. Business ethics: Readings and cases in corporate morality: 56-65. Boston: McGraw-Hill.

Freeman, R. E., \& Werhane, P. H. 1999. Business ethics: The state of the art. International Journal of Management Reviews, 1: 1-16.

Jones, C., Parker, M., \& Ten Bos, R. 2005. For business ethics. London: Routledge.

Lakoff, G., \& Johnson, M. 1999. Philosophy in the flesh. The embodied mind and its challenge to Western thought. New York: Basic Books.

MacIntyre, A. 1981. After virtue. London: Duckworth.

MacIntyre, A. 1999. Social structures and their threats to moral agency, Philosophy today, 74: 311-29.

Mills, A. E., Rorty, M. V. \& Werhane, P. H. 2003. Complexity and the role of ethics in health care. Emergence. A Journal of Complexity Issues in Organization and Management, 5(3): 6-21. 
Olivier, B. 2003. Discourse, agency and the question of evil. South African Journal of Philosophy, 22: 328-46.

Petersen, V. C. 1999a. Judging with our guts: The importance of an ineffable social grammar. Working paper 99-12. The Aarhus School of Business, Aarhus, Denmark.

Petersen, V. C. 1999b. Thinking with our hands: The importance of tacit, non-algorithmic knowledge. Working paper 99-10. The Aarhus Business School, Aarhus, Denmark.

Petersen, V. C. 2002. Beyond rules in business and society. Northampton, MA: Edward Elgar.

Phillips, R. 2003. Stakeholder Legitimacy. Business Ethics Quarterly, 13: 25-41.

Phillips, R., Freeman, R. E., \& Wicks, A. C. 2003. What stakeholder theory is not. Business Ethics Quarterly, 13: 479-502.

Rorty, R. 1999. Philosophy and social hope. London: Penguin Books.

Taylor, M. C. 2001. The moment of complexity: Emerging network culture. Chicago: University of Chicago Press.

Taylor, M. C. 2004. Confidence games: Money and markets in a world without redemption. Chicago: University of Chicago Press.

Werhane, P. H. 1999. Moral imagination and management decision-making. New York: Oxford University Press. 
Copyright of Business Ethics Quarterly is the property of Philosophy Documentation Center and its content may not be copied or emailed to multiple sites or posted to a listserv without the copyright holder's express written permission. However, users may print, download, or email articles for individual use. 